\title{
Regiodivergent synthesis of functionalized pyrimidines and imidazoles through phenacyl azides in deep eutectic solvents
}

\author{
Paola Vitale ${ }^{*}$, Luciana Cicco ${ }^{1}$, Ilaria Cellamare ${ }^{1}$, Filippo M. Perna ${ }^{1}$, Antonio Salomone ${ }^{2,3}$ \\ and Vito Capriati ${ }^{*}$
}

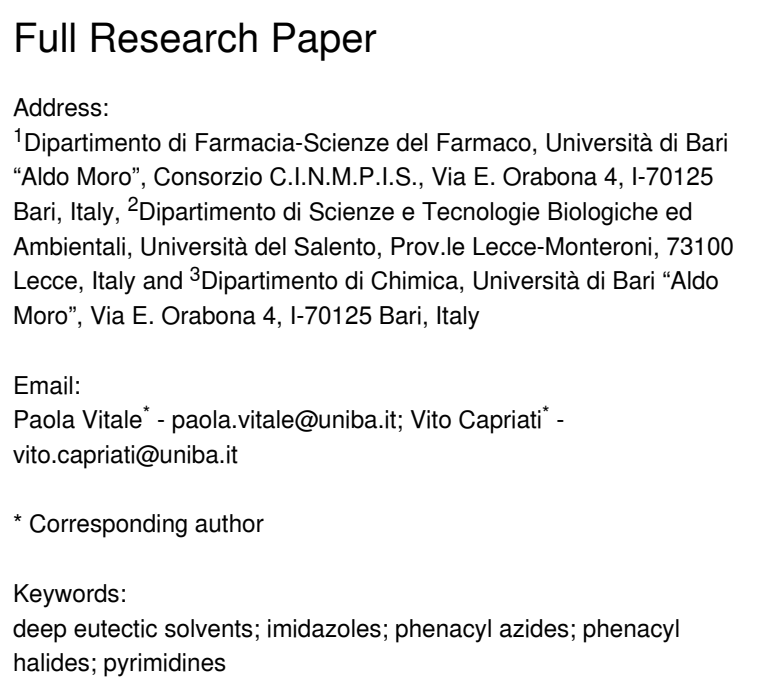

Beilstein J. Org. Chem. 2020, 16, 1915-1923.

doi:10.3762/bjoc.16.158

Received: 30 May 2020

Accepted: 20 July 2020

Published: 05 August 2020

This article is part of the thematic issue "Green chemistry II".

Guest Editor: L. Vaccaro

(C) 2020 Vitale et al.; licensee Beilstein-Institut. License and terms: see end of document.

\begin{abstract}
We report that phenacyl azides are key compounds for a regiodivergent synthesis of valuable, functionalized imidazole (32-98\% yield) and pyrimidine derivatives (45-88\% yield), with a broad substrate scope, when using deep eutectic solvents [choline chloride $(\mathrm{ChCl}) /$ glycerol $(1: 2 \mathrm{~mol} / \mathrm{mol})$ and $\mathrm{ChCl} /$ urea $(1: 2 \mathrm{~mol} / \mathrm{mol})]$ as environmentally benign and non-innocent reaction media, by modulating the temperature $\left(25\right.$ or $\left.80^{\circ} \mathrm{C}\right)$ in the presence or absence of bases $\left(\mathrm{Et}_{3} \mathrm{~N}\right)$.
\end{abstract}

\section{Introduction}

In a world with dwindling petroleum resources, the setting up of more and more sustainable routes for the preparation of heterocyclic compounds is an ongoing synthetic endeavor as these scaffolds are ubiquitous motifs in many biologically active compounds and pharmaceuticals. In this context, in the last decades, the so-called deep eutectic solvents (DESs) have received an increasing attention due to their biodegradability, high thermal stability, non-flammability, and low volatility. These are mixtures usually obtained from the combination of 2 or 3 safe, inexpensive and nature-inspired components able to engage in reciprocal hydrogen-bond interactions, and that form fluids at a specified mixing ratio at the desired temperature. Owing to the broad tunability of their physicochemical properties and the ability to act not only as solvents but also as catalysts and reagents, DESs have progressively replaced toxic and volatile organic solvents (VOCs) in countless heterocyclodehydration processes and multicomponent reactions (MCRs) [1-3].

As part of our ongoing research in DES chemistry, we reported recently on the preparation of valuable heterocycles by 
(a) nucleophilic substitution (tetrahydrofuran derivatives) [4],

(b) heterocyclodehydration reactions (2-aminoimidazoles, 2-pyrazinones, benzoxazines, thiophenes) [5-8], (c) carbon-sulfur bond-forming reactions [9], (d) directed ortho-metalation and nucleophilic acyl substitution strategies [10], (e) Pd-catalyzed aminocarbonylation of aryl iodides, Suzuki-Miyaura and Sonogashira cross-coupling reactions [1113], (f) $\mathrm{Cu}$-catalyzed $\mathrm{C}-\mathrm{N}$ coupling reactions [14], and (g) heterogeneous "click" cycloaddition reactions [15] using DESs as environmentally responsible and non-innocent reaction media. Telescoped, one-pot transformations of phenacyl halides to symmetrical 2,5-disubstituted pyrazines (A), through phenacyl azides as intermediates, were also found to take place smoothly using such neoteric solvents (Scheme 1, path a) [16].

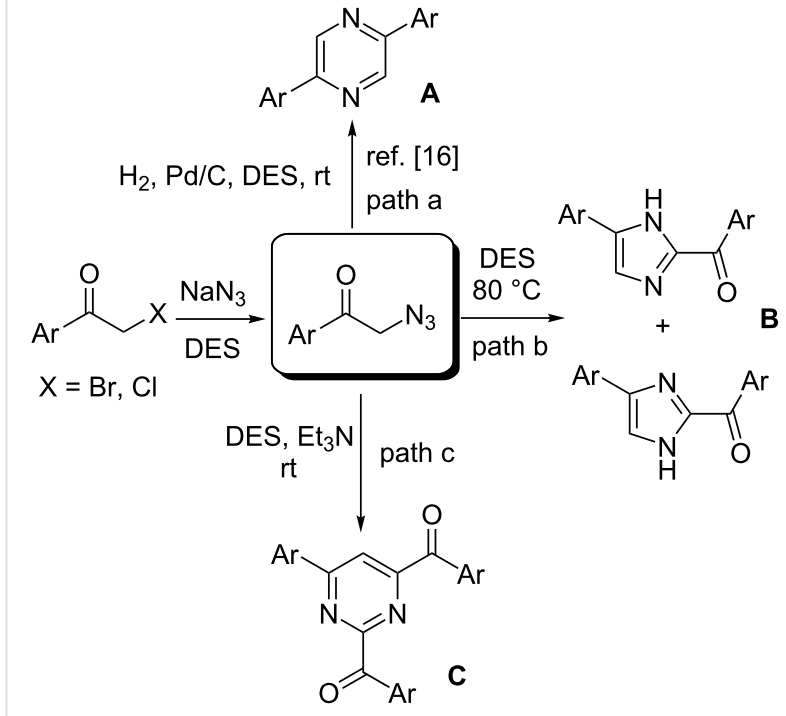

Scheme 1: One-pot synthesis of 2,5-diarylpyrazines (A) (path a) or 2-aroyl-(4 or 5)-aryl-(1H)-imidazoles (B) (path b), or 2,4-diaroyl-6arylpyrimidines $(\mathbf{C})$ (path $\mathrm{c}$ ) in DES from phenacyl azides $(\mathrm{rt}=$ room temperature)

Among nitrogen-containing heterocyles, imidazoles and pyrimidines are important structural scaffolds commonly found in natural products $[17,18]$, light-emitting devices $[19,20]$, and pharmacologically active compounds as anticancer, anti-inflammatory, antitubercular, antihypertensive, antihistaminic, antiobesity, antiviral, and other medicinal agents [21-27]. Herein, we wish to report that either 2-aroylimidazoles (B) (Scheme 1, path b) or 2,4-diaroylpyrimidines (C) (Scheme 1, path c) can regioselectively be prepared from the same phenacyl azide as starting material by properly selecting the nature of the eutectic mixture and the temperature, in the presence or absence of bases.

To the best of our knowledge, while there are a few reports for the synthesis of 2-aroylimidazoles (a) through the condensation of $\alpha$-azido ketones in $\mathrm{iPrOH}$ in the presence of potassium ethylxanthate as a catalyst [28], (b) by exploiting the reaction of arylglyoxals with an excess amount of ammonium acetate in water [29], (c) by the cathodic reduction of 2-azido-1phenylethanone in a $\mathrm{DMF} / \mathrm{LiClO}_{4}$ medium [30], (d) by radical chain reactions of $\alpha$-azido ketones with tributyltin hydride [31], or (e) by a modified Radziszewski's synthesis when using phenylglyoxals, benzaldeydes, and ammonium acetate as ammonia source in acetic acid or methylene chloride or $N, N$ dimethylformamide as the solvent [32], there are no adequate studies covering the preparation of aroylpyrimidines. In 1995, Yamamoto et al. reported the direct introduction of acyl groups into pyrimidine rings by reacting trimethylstannyl derivatives with acylformyl chlorides in dry benzene under a $\mathrm{N}_{2}$ stream [33].

\section{Results and Discussion}

During our studies on the synthesis of symmetrical pyrazines, we observed that phenacyl bromide (1a, $1.5 \mathrm{mmol}$ ) could be almost quantitatively converted into phenacyl azide (2a, 97\% yield), within $4 \mathrm{~h}$, when treated with $\mathrm{NaN}_{3}(1.65 \mathrm{mmol})$ as the azide source in a choline chloride $(\mathrm{ChCl}) / \mathrm{glycerol}$ (Gly) $(1: 2 \mathrm{~mol} / \mathrm{mol})$ eutectic mixture at room temperature $\left(\mathrm{rt}, 25^{\circ} \mathrm{C}\right)$ (Scheme 2) [16]. By warming the mixture up to $50{ }^{\circ} \mathrm{C}$, the yield of $2 \mathrm{a}$ dropped to $89 \%$ after $1 \mathrm{~h}$, and we noticed in the crude the appearance of an additional product, which was detected as a fluorescent spot on TLC, whose amount increased by increasing the temperature. After $4 \mathrm{~h}$ warming at $50{ }^{\circ} \mathrm{C}$, we were able to isolate by column chromatography on silica gel a product which was characterized as 2-benzoyl-(4 or 5)-phenyl-( $1 H)$ imidazole (3a/3a', Scheme 2). This adduct was formed as a mixture of two tautomers (3a and $\mathbf{3 a} \mathbf{a}^{\prime}$; $\mathbf{3 a} / \mathbf{3} \mathbf{a}^{\prime}$ ratio: 57:43, Supporting Information File 1) $[28,29]$ in an overall $16 \%$ yield, the remaining being mainly $\mathbf{2 a}$, which was isolated in $75 \%$ yield (Scheme 2). We thus became interested in improving the yield of $\mathbf{3 a} / \mathbf{3} \mathbf{a}^{\prime}$.

After careful evaluation of the reaction parameters (temperature and time) and the amount of $\mathrm{NaN}_{3}$ used, we found that the treatment of phenacyl chloride (1b) with $\mathrm{NaN}_{3}$ (1.5 equiv) in $\mathrm{ChCl} / \mathrm{Gly}$ at $80{ }^{\circ} \mathrm{C}$ gave the best results, as it provided the adducts $\mathbf{3 a} / \mathbf{3 a}$ ' in an overall $88 \%$ yield after $12 \mathrm{~h}$ reaction time (Table 1, entries 1-4). Of note, imidazoles $\mathbf{3 a} / \mathbf{3} \mathbf{a}^{\prime}$ were found to precipitate directly from the aforementioned eutectic mixture during the reaction, and thus they could be isolated by simple decantation or centrifugation and washing with a few drops of EtOAc or $\mathrm{Et}_{2} \mathrm{O}$. This procedure left azide 2a in solution. The latter could be quantified (10\% yield) by simple dilution with an equal volume mixture of water and EtOAc, followed by the separation of the organic layer from water, and removal of the volatiles under reduced pressure. 


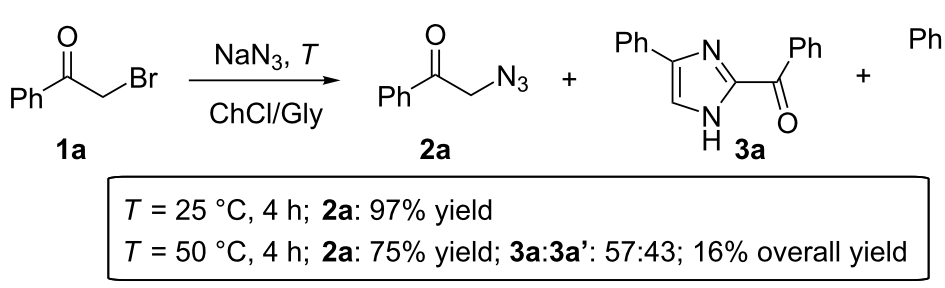

Scheme 2: Transformation of phenacyl bromide (1a) in ChCl/Gly into phenacyl azide (2a) and 2-benzoyl-(4 or 5)-phenyl-(1H)-imidazole (3a and 3a') depending on the temperature.

Table 1: Optimization of the reaction conditions for the synthesis of $3 a / 3 a^{\prime} .^{a}$

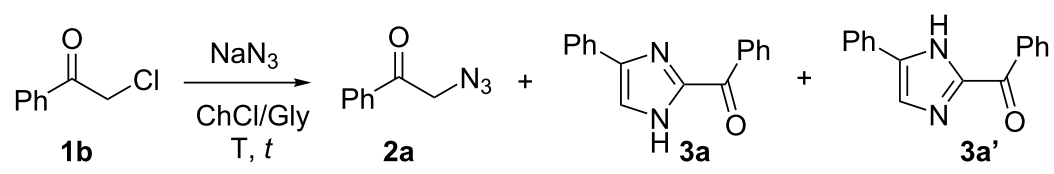

\begin{tabular}{llllll}
\hline entry & $T\left({ }^{\circ} \mathrm{C}\right)$ & $t(\mathrm{~h})$ & $\mathrm{NaN}_{3}$ (equiv) & 2a yield $(\%)^{\mathrm{b}}$ & $\mathbf{3 a}^{\mathrm{a}} \mathbf{3 a} \mathbf{a}^{\prime}$ yield $(\%)^{\mathrm{b}}$ \\
\hline 1 & 80 & 4 & 1.2 & 37 & 55 \\
2 & 100 & 16 & 1.2 & 7 & $60^{\mathrm{C}}$ \\
3 & 80 & 16 & 0.9 & 68 & 32 \\
4 & 80 & 12 & 1.5 & 10 & 88 \\
\hline
\end{tabular}

aReaction conditions: 1 b $(0.5 \mathrm{mmol})$, ChCl/Gly $(1.0 \mathrm{~g})$; byield refers to products isolated after column chromatography on silica gel; ${ }^{\mathrm{c}} 15 \%$ of 2,4 -dibenzoyl-6-phenylpyrimidine was also isolated (see main text and Table 2).

To examine the scope and limitation of this transformation, various functionalized phenacyl halides $(\mathbf{1 c}-\mathbf{i})$ were tested as substrates. As can be seen from the results compiled in Scheme 3, the reaction is amenable to "neutral" (Me), electronwithdrawing $(\mathrm{Cl}, \mathrm{Br}, \mathrm{CN})$ and electron-donating $(\mathrm{MeO}, \mathrm{OH})$ substituents as the desired imidazoles $\mathbf{3 b} \mathbf{b} \mathbf{3} \mathbf{b}^{\mathbf{}} \mathbf{-} \mathbf{3 h}$ were isolated in $78-98 \%$ yield. The presence of additional halogen groups such as chlorine and bromine in $\mathbf{3 c} / \mathbf{3} \mathbf{c}^{\prime}$ and $\mathbf{3 d}$ allows further downstream diversification by cross-coupling reactions. A 4-fluoro-substituted phenacyl chloride as well as a bromomethyl 2-naphthyl ketone proved to be competent substrates as well, thus furnishing the corresponding imidazoles $\mathbf{3 i} / \mathbf{3 i}$ ' and $\mathbf{3 j}$ in $67-87 \%$ yield. Conversely, a phenacyl halide decorated with an additional phenyl group at the para-position delivered the expected adduct $\mathbf{3 k} / \mathbf{3} \mathbf{k}^{\prime}$ in $32 \%$ yield even by prolonging the reaction time to $16 \mathrm{~h}$, most probably because of the poor solubility in the eutectic mixture and/or the higher thermal stability towards the loss of $\mathrm{N}_{2}$ (vide infra) of the corresponding phenacyl azide $\mathbf{2 k}$ as it is formed. The latter was indeed isolated as the main product ( $68 \%$ yield, Scheme 3$)$.

A plausible mechanism for the formation of the 2-aroylimidazoles $\mathbf{3} / \mathbf{3}^{\prime}$ is depicted in Scheme 4. A key intermediate may be the in situ generated $\alpha$-imino ketone $\mathbf{5}$. The latter is known to undergo dimerization to give $\mathbf{6}$ followed by dehydration. The two tautomers $\mathbf{3} / \mathbf{3}^{\prime}$ ' would most probably originate by two competitive pathways (a and b; Scheme 4) via a [1,5]-hydrogen shift $[28,29]$. Hydrogen-bond catalysis promoted by DES components may be playing an important role in favoring the loss of nitrogen under mild conditions from a putative azide tautomer 4, the latter deriving from the corresponding $\alpha$-phenacyl azide precursor 2 via an acid-catalyzed enolization process [34]. The pyrolysis of $\alpha$-azido ketones in conventional VOCs (trichlorobenzene) is known to take place under harsh conditions, which are based on heating the mixture between $180{ }^{\circ} \mathrm{C}$ and $240{ }^{\circ} \mathrm{C}$ [35].

The investigation of the thermal stability of phenacyl azides 2 led to the fortuitous discovery of the competitive formation of a different heterocycle. Indeed, while phenacyl azide (2a) was stable per se in a $\mathrm{ChCl} / \mathrm{Gly}$ mixture after stirring at $\mathrm{rt}$ for $12 \mathrm{~h}$, a new fluorescent spot was detected on TLC plate in the presence of an excess of $\mathrm{Et}_{3} \mathrm{~N}$ ( 3 equiv). After column chromatography on silica gel, we were able to isolate a new product that was characterized as 2,4-dibenzoyl-6-phenylpyrimidine (7a, 55\% yield) in addition to $\mathbf{3 a} / \mathbf{3} \mathbf{a}^{\prime}$ ( $26 \%$ yield), the remaining being starting material only (conversion: $81 \%$, Table 2 , entry 1 ). The employment of $\mathrm{ChCl} /$ urea $(1: 2 \mathrm{~mol} / \mathrm{mol})$ as the eutectic mix- 


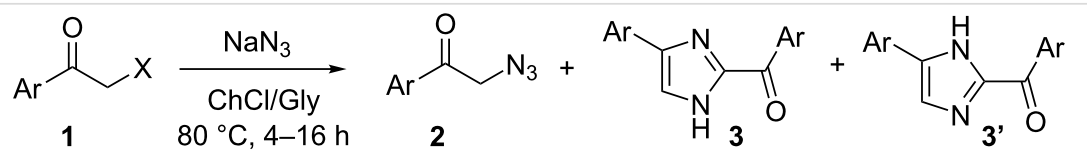

1c,2b,3b/3b': $\mathrm{Ar}=4-\mathrm{MeC}_{6} \mathrm{H}_{4} ; \mathbf{1 d}, \mathbf{2 c}, \mathbf{3 c} / \mathbf{3} \mathbf{c}^{\prime}: \mathrm{Ar}=4-\mathrm{ClC}_{6} \mathrm{H}_{4} ; \mathbf{1 e}, \mathbf{2 d}, \mathbf{3 d}: \mathrm{Ar}=4-\mathrm{BrC}_{6} \mathrm{H}_{4} ; \mathbf{1 f}, \mathbf{2 e}, \mathbf{3 e}: \mathrm{Ar}=4-\mathrm{CNC}_{6} \mathrm{H}_{4}$ 1g,2f,3f/3f': $\mathrm{Ar}=4-\mathrm{MeOC}_{6} \mathrm{H}_{4} ; \mathbf{1 h}, \mathbf{2 g}, \mathbf{3 g} / \mathbf{3 g}$ : $\mathrm{Ar}=2,5-(\mathrm{MeO})_{2} \mathrm{C}_{6} \mathrm{H}_{3} ; \mathbf{1 i}, \mathbf{2 h}, \mathbf{3 h}: \mathrm{Ar}=2-\mathrm{OHC}_{6} \mathrm{H}_{4} ; \mathbf{1 j}, \mathbf{2 i}, \mathbf{3 i} / \mathbf{3 i}: \mathrm{Ar}=4-\mathrm{FC}_{6} \mathrm{H}_{4}$ 1k,2j,3j: $\mathrm{Ar}=2$-naphthyl; 11,2k,3k/3k': $\mathrm{Ar}=4-\mathrm{PhC}_{6} \mathrm{H}_{4}$<smiles>Cc1ccc(C(=O)c2nc(-c3ccc(C)cc3)c[nH]2)cc1</smiles><smiles>O=C(c1ccc(Cl)cc1)c1nc(-c2ccc(Cl)cc2)c[nH]1</smiles>

$\mathbf{3 b}: \mathbf{3} \mathbf{b}^{\prime}=93: 7(78 \%) ; \mathbf{2 b}: 18 \%$ $\mathrm{X}=\mathrm{Br} ; 4 \mathrm{~h}$
$3 c: 3 c^{\prime}=88: 12(86 \%) ; 2 c: 10 \%$ $\mathrm{X}=\mathrm{Cl} ; 4 \mathrm{~h}$<smiles>O=C(c1ccc(Br)cc1)c1nc(-c2ccc(Br)cc2)c[nH]1</smiles>

3d: $86 \% ; 2 d: 8 \%$ $\mathrm{X}=\mathrm{Cl} ; 4 \mathrm{~h}$<smiles>N#Cc1ccc(C(=O)c2nc(-c3ccc(C#N)cc3)c[nH]2)cc1</smiles>

3e: $78 \%$; 2 e: $3 \%$ $\mathrm{X}=\mathrm{Br} ; 4 \mathrm{~h}$<smiles>COc1ccc(C(=O)c2nc(-c3ccc(OC)cc3)c[nH]2)cc1</smiles>

3f:3f' = 50:50 (98\%) $\mathrm{X}=\mathrm{Cl}, 4 \mathrm{~h}$<smiles>O=C(c1ccc(F)cc1)c1nc(-c2ccc(F)cc2)c[nH]1</smiles>

$3 \mathbf{i}: 3 i^{\prime}=90: 10(87 \%) ; 2 i: 4 \%$ $\mathrm{X}=\mathrm{Cl} ; 4 \mathrm{~h}$<smiles>COc1ccc(OC)c(C(=O)c2nc(-c3cc(OC)ccc3OC)c[nH]2)c1</smiles>

$\mathbf{3 g}: \mathbf{3} \mathbf{g}^{\prime}=93: 7$ (94\%); $\mathbf{2 g}: \mathbf{4} \%$ $\mathrm{X}=\mathrm{Cl} ; 4 \mathrm{~h}$<smiles>O=C(c1ccc2ccccc2c1)c1nc(-c2ccc3ccccc3c2)c[nH]1</smiles>

3j: $67 \% ; 2 \mathbf{j}: 31 \%$ $\mathrm{X}=\mathrm{Br} ; 4 \mathrm{~h}$<smiles>O=C(c1nc(-c2ccccc2O)c[nH]1)c1ccccc1O</smiles>

3h: $71 \%$; 2 h: $4 \%$ $\mathrm{X}=\mathrm{Br} ; 4 \mathrm{~h}$<smiles>O=C(c1ccc(-c2ccccc2)cc1)c1nc(-c2ccc(-c3ccccc3)cc2)c[nH]1</smiles>

3k:3k' = 79:21 (32\%); 2k: 68\% $\mathrm{X}=\mathrm{Br} ; 16 \mathrm{~h}$

Scheme 3: Synthesis of 2-aroyl-(4 or 5)-aryl-(1H)-imidazoles 3. Scope of the reaction. Typical conditions: $1(0.5 \mathrm{mmol}), \mathrm{NaN} 3(0.75 \mathrm{mmol})$, ChCl/Gly $(1.0 \mathrm{~g}), 80^{\circ} \mathrm{C}, 4-16 \mathrm{~h}$; yield refers to products isolated after column chromatography on silica gel; only one tautomer has been depicted for simplicity; imidazoles $\mathbf{3 c} / \mathbf{3} \mathbf{c}^{\prime}, \mathbf{3 i} / \mathbf{3 i}$ ', $\mathbf{3} \mathbf{j}, \mathbf{3 k} / \mathbf{3} \mathbf{k}^{\prime}$ were found to precipitate as they formed, and were isolated by filtration/centrifugation and washing with a few drops of AcOEt or $\mathrm{Et}_{2} \mathrm{O}$; synthesis of imidazoles $\mathbf{3 k} / \mathbf{3} \mathbf{k}^{\prime}: 10 \%(\mathrm{w} / \mathrm{w}) \mathrm{EtOH}$ was added to the eutectic mixture to improve the solubility of $\mathbf{2 k}$.

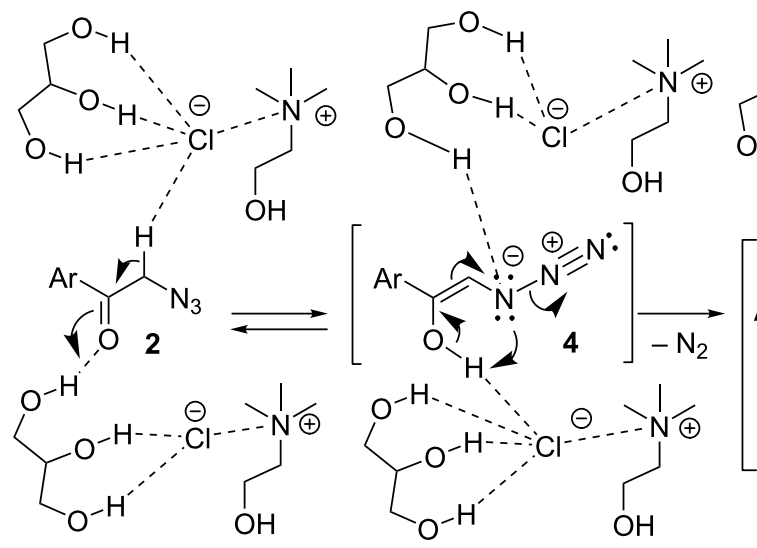

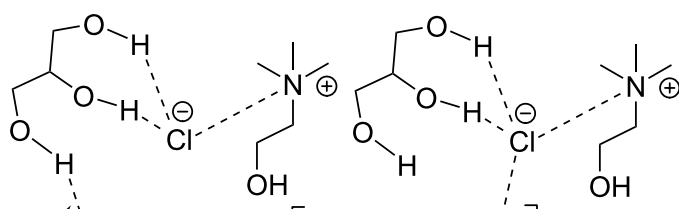

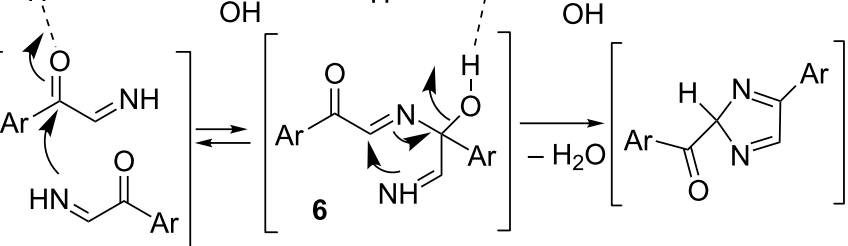<smiles>O=C([Al]c1ccccc1)c1nc(Br)c[nH]1</smiles>

Scheme 4: Proposed mechanism for the formation of 2-aroyl-(4 or 5)-aryl-(1H)-imidazoles 3/3' from $\alpha$-phenacyl azides 2 in ChCl/Gly. 
Table 2: Investigation of the reaction conditions in the synthesis of $7 a^{a}$

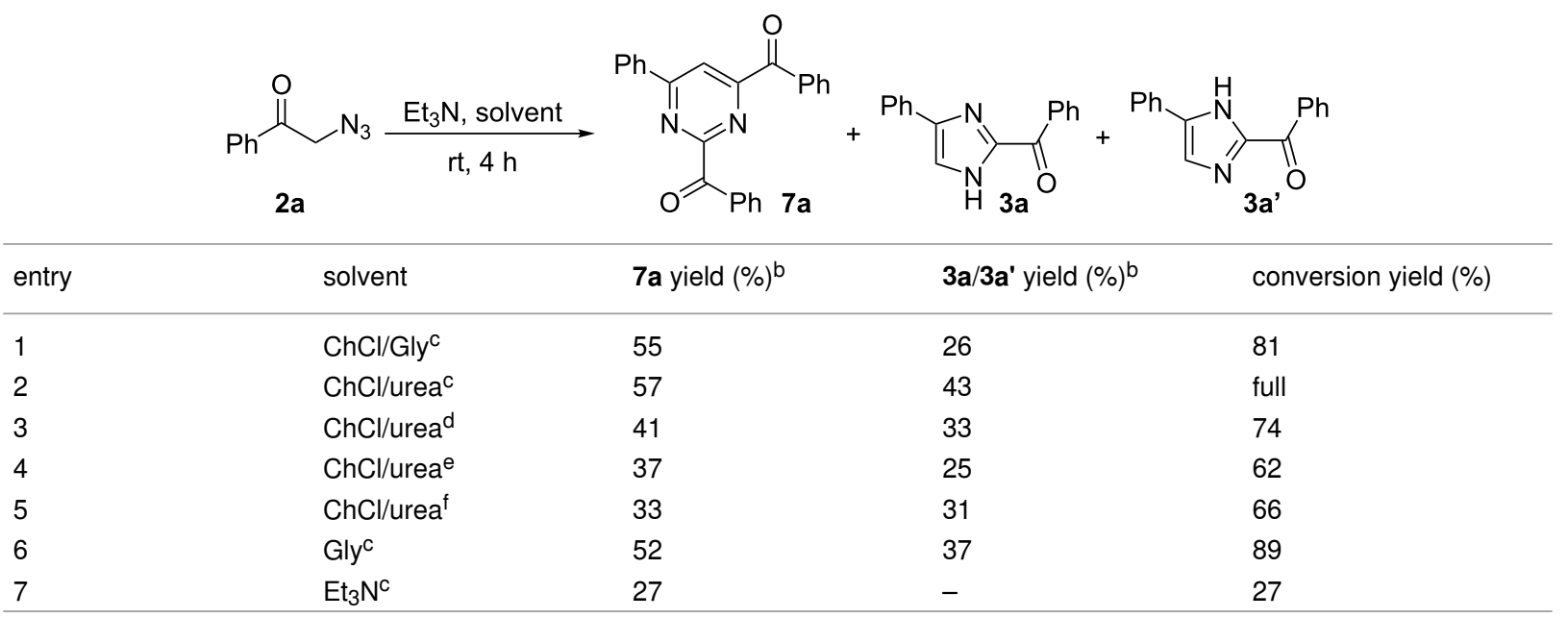

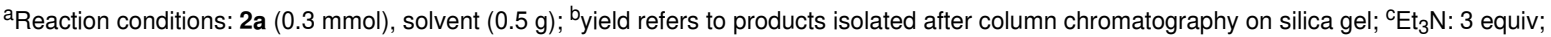
${ }^{d} \mathrm{Et}_{3} \mathrm{~N}$ : 2 equiv; ${ }^{e} \mathrm{E}{ }_{3} \mathrm{~N}: 1$ equiv; ${ }^{\mathrm{f}} \mathrm{K}_{2} \mathrm{CO}_{3}: 3$ equiv.

ture provided $\mathbf{7 a}$ in $57 \%$ yield and $\mathbf{3 a} / \mathbf{3} \mathbf{a}^{\prime}$ in $43 \%$ yield, but with full conversion (Table 2, entry 2). By lowering the equivalents of $\mathrm{Et}_{3} \mathrm{~N}$ up to 1, or alternatively using $\mathrm{K}_{2} \mathrm{CO}_{3}$ (3 equiv) as a base, in $\mathrm{ChCl} /$ urea, the yield of $7 \mathbf{a}$ dropped down up to $33 \%$ and that of $\mathbf{3 a} / \mathbf{3} \mathbf{a}^{\prime}$ up to $25 \%$ (Table 2, entries 3-5). By changing the solvent to pure Gly, 7a and 3a/3a' now formed in 52 and 37\% yield, respectively (Table 2, entry 6). When $\mathrm{Et}_{3} \mathrm{~N}$ ( 3 equiv) was alternatively used as the sole solvent, the formation of $7 \mathbf{a}$ was suppressed dramatically ( $27 \%$ yield, Table 2 , entry 7 ) [36]. This last result is consistent with a synergistic cooperation of the basic $\mathrm{ChCl} /$ urea eutectic mixture [37] with $\mathrm{Et}_{3} \mathrm{~N}$ in promoting the transformation at rt. $\alpha$-Azido ketones are, indeed, known to be highly base sensitive and to undergo a base-promoted loss of nitrogen to form $\alpha$-imino ketones upon protonation [38].

A plausible mechanism for the formation of pyrimidine derivative $7 \mathbf{a}$ from $\mathbf{2 a}$, in competition with imidazoles $\mathbf{3 a} / \mathbf{3} \mathbf{a}^{\prime}$, is depicted in Scheme 5.

The key intermediate 5a, formed by elimination of nitrogen from the enol-azide $\mathbf{4 a}$, would undergo either dimerization to give $\mathbf{6 a}$, and then imidazoles $\mathbf{3 a} / \mathbf{3} \mathbf{a}^{\prime}$ after cyclization and dehydration (see Scheme 5), or trimerization to afford adduct $\mathbf{8 a}$ further to an additional attack of $\mathbf{5 a}$ to the internal imino group

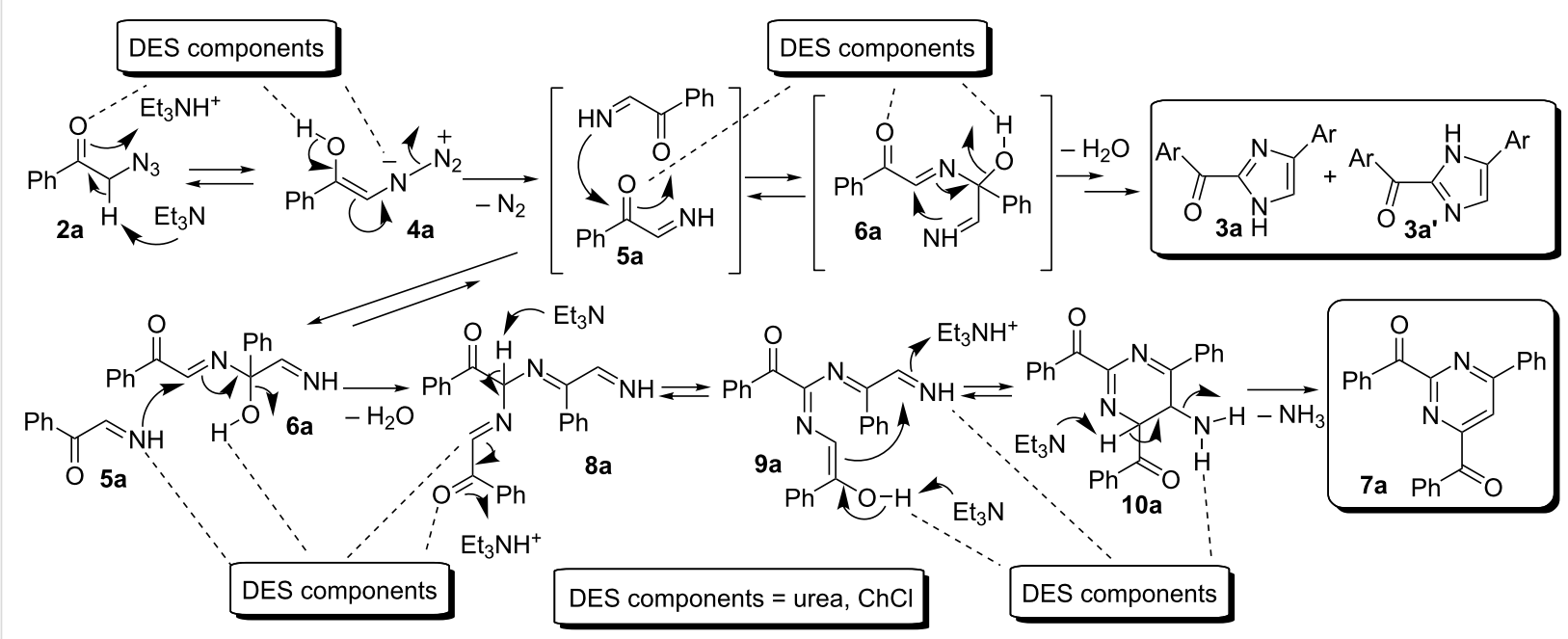

Scheme 5: Proposed mechanism for the formation of 2-benzoyl-(4 or 5)-phenyl-(1H)-imidazoles 3a/3a' and 2,4-dibenzoyl-6-phenylpyrimidine (7a) from $\alpha$-phenacyl azide (2a) in $\mathrm{ChCl} /$ urea in the presence of $\mathrm{Et}_{3} \mathrm{~N}$. 
of $\mathbf{6 a}$ and dehydration. Consecutive tautomerization, followed by an intramolecular nucleophilic attack to the terminal imino group of 9a, provides cyclized adduct 10a, and finally pyrimidine derivative $7 \mathbf{a}$ by aromatization/elimination of $\mathrm{NH}_{3}$. To the best of our knowledge, this is the first one-pot synthesis of functionalized pyrimidines using phenacyl azides as the sole starting material [39]. Variation of the phenacyl azides was next investigated in the preparation of various pyrimidines 7 (Scheme 6).

The results shown in Scheme 6 demonstrate that this protocol allows the use of phenacyl azides as starting material also for the preparation of a variety of 2,4,6-trisubstituted pyrimidines. The cyclotrimerization of phenacyl azides containing an alkyl group (4-Me, 2b), halides (4-Cl, 4-Br and 4-F, 2c, d, and $\mathbf{2 i}$ ) or strong electron-withdrawing groups $\left(2-\mathrm{CF}_{3}, 4-\mathrm{CF}_{3}, \mathbf{2 l}, \mathbf{m}\right)$ occurs smoothly at $\mathrm{rt}$ generally within $4 \mathrm{~h}$ in a $\mathrm{ChCl} /$ urea eutectic mixture, thereby providing the desired pyrimidines $\mathbf{7 b}-\mathbf{h}$ in $45-88 \%$ yield. Variable amounts of difunctionalized imidazoles 3/3' (20-40\%), deriving from a dimerization process, also formed competitively in some cases under the aforementioned conditions. The latter, however, could be easily isolated by column chromatography. The presence of strong electron-donating groups like $\mathrm{MeO}$ was not tolerated. Indeed, phenacyl azides $\mathbf{2 f}$, and $\mathbf{2 g}$ remained unreacted when stirred in $\mathrm{ChCl} / \mathrm{urea}$ at $\mathrm{rt}$ even for $12 \mathrm{~h}$.

\section{Conclusion}

In summary, we have shown that phenacyl halides can be straightforwardly converted, via phenacyl azides, into valuable 2-aroyl-(4 or 5)-aryl-( $1 \mathrm{H})$-imidazoles when a solution in $\mathrm{ChCl} /$ Gly (1:2) is heated to $80{ }^{\circ} \mathrm{C}$ for $4-16 \mathrm{~h}$ in the presence of $\mathrm{NaN}_{3}$ (1.5 equiv). In most cases, their isolation can be performed by a very gentle procedure: decantation/centrifugation as soon as they form from the above eutectic mixture. The reaction proceeds in very good yields (67-98\%) when phenacyl azides are soluble in the eutectic mixture and is applicable to a range of substrates. Phenacyl azides, in turn, can also be competitively converted into 2,4-diaroyl-6-arylpyrimidines (45-88\% yield) via an unprecedented cyclotrimerization reaction the key intermediate $\alpha$-imino ketone undergoes when a solution in<smiles>CCCCCCCCCCCC(=O)Br</smiles>

2<smiles>O=C(Br)c1cc(Br)nc(C(=O)Br)n1</smiles><smiles>O=C(Br)c1nc(Br)c[nH]1</smiles><smiles>O=C(Br)c1ncc(Br)[nH]1</smiles>

2b,3b/3b',7b: $\mathrm{Ar}=4-\mathrm{MeC}_{6} \mathrm{H}_{4} ; \mathbf{2 c}, 3 \mathbf{3} / \mathbf{3} \mathbf{c}^{\prime}, \mathbf{7 c}: \mathrm{Ar}=4-\mathrm{ClC}_{6} \mathrm{H}_{4} ; \mathbf{2 d}, \mathbf{7 d}: \mathrm{Ar}=4-\mathrm{BrC}_{6} \mathrm{H}_{4} ; \mathbf{2 h}, \mathbf{7 e}: \mathrm{Ar}=2-\mathrm{OHC}_{6} \mathrm{H}_{4}$ 2i,3i/3i',7f: $\mathrm{Ar}=4-\mathrm{FC}_{6} \mathrm{H}_{4} ; \mathbf{2 l}, \mathbf{7 g}: \mathrm{Ar}=2-\mathrm{CF}_{3} \mathrm{C}_{6} \mathrm{H}_{4} ; 2 \mathrm{~m}, 3 \mathrm{I} / 3 \mathrm{I}^{\prime}, 7 \mathrm{~h}: \mathrm{Ar}=4-\mathrm{CF}_{3} \mathrm{C}_{6} \mathrm{H}_{4}$<smiles>Cc1ccc(C(=O)c2cc(C(=O)c3ccc(C)cc3)nc(-c3ccc(C)cc3)n2)cc1</smiles>

7b: $52 \% ; 3 \mathbf{3 b} / \mathbf{3 b}: \mathbf{2 9 \%}$ conversion: $81 \%$<smiles>O=C(c1ccc(F)cc1)c1cc(-c2ccc(F)cc2)nc(C(=O)c2ccc(F)cc2)n1</smiles>

7f: $61 \% ; 3 i / 3 i ': 36 \%$ conversion: $97 \%$<smiles>O=C(c1ccc(Br)cc1)c1cc(-c2ccc(Br)cc2)nc(C(=O)c2ccc(Br)cc2)n1</smiles><smiles>O=C(c1cc(-c2ccccc2O)nc(C(=O)c2ccccc2O)n1)c1ccccc1O</smiles>

7c: $45 \%$; 3c/3c': $40 \%$ conversion: $85 \%$ 7d: $82 \%$; conversion: $82 \%$ 7e: $75 \%$; conversion: $82 \%$<smiles>O=C(c1cc(-c2ccccc2C(F)(F)F)nc(C(=O)c2ccccc2C(F)(F)F)n1)c1ccccc1C(F)(F)F</smiles>

7g: $88 \%$; conversion: $88 \%$<smiles>O=C(c1ccc(C(F)(F)F)cc1)c1cc(-c2ccc(C(F)(F)F)cc2)nc(C(=O)c2ccc(C(F)(F)F)cc2)n1</smiles>

7h: $69 \%$; 3I/3I': $20 \%$ conversion: $88 \%$ 
$\mathrm{ChCl} /$ urea is stirred at $\mathrm{rt}$ for $4 \mathrm{~h}$ in the presence of $\mathrm{Et}_{3} \mathrm{~N}$ ( 3 equiv) as a base. These cyclizations proved to be relatively sensitive to the electronic properties of the starting phenacyl azides as they did not take place in the presence of strong electron-donating groups like $\mathrm{MeO}$. Studies to expand even more the scope and the selectivity of such DES-promoted heterocyclization reactions and to elucidate their mechanism are in progress.

\section{Experimental}

\section{General methods}

Deep eutectic solvents [choline chloride $(\mathrm{ChCl}) /$ glycerol (Gly) $(1: 2 \mathrm{~mol} / \mathrm{mol})$; choline chloride $(\mathrm{ChCl}) /$ urea $(1: 2 \mathrm{~mol} / \mathrm{mol})]$ were prepared by heating under stirring up to $80{ }^{\circ} \mathrm{C}$ for 10-15 min the corresponding individual components until a clear solution was obtained. ${ }^{1} \mathrm{H}$ NMR and ${ }^{13} \mathrm{C}$ NMR spectra were recorded on a Varian Mercury 300 or on a Bruker 400 or $600 \mathrm{MHz}$ spectrometer and chemical shifts are reported in parts per million ( $\delta$ ); $\mathrm{CDCl}_{3},\left(\mathrm{CD}_{3}\right)_{2} \mathrm{CO}$ and $\left(\mathrm{CD}_{3}\right)_{2} \mathrm{SO}$ were used as solvents. GC-MS analyses were performed on a HP 6890 gas chromatograph, Series II by using a HP1 column (methyl siloxane; $30 \mathrm{~m} \times 0.32 \mathrm{~mm} \times 0.25 \mu \mathrm{m}$ film thickness) equipped with a mass-selective detector operating at $70 \mathrm{eV}$. Analytical thin-layer chromatography (TLC) was carried out on pre-coated $0.25 \mathrm{~mm}$ thick plates of Kieselgel $60 \mathrm{~F}_{254}$; visualization was accomplished by UV light ( $254 \mathrm{~nm}$ ) or by spraying with a solution of $5 \%(\mathrm{w} / \mathrm{v})$ ammonium molybdate and $0.2 \%(\mathrm{w} / \mathrm{v})$ cerium(III) sulfate in $100 \mathrm{~mL} 17.6 \%(\mathrm{w} / \mathrm{v})$ aq. sulfuric acid and heating to $473 \mathrm{~K}$ until blue spots appeared. Column chromatography was conducted by using silica gel 60 with a particle size distribution of 40-63 $\mu \mathrm{m}$ and 230-400 ASTM, using hexane/ EtOAc mixtures as the eluent. High-resolution mass spectrometry (HRMS) analyses were performed using a Bruker microTOF QII mass spectrometer equipped with an electrospray ion source (ESI). $\mathrm{NaN}_{3}, 2$-haloketones, and all other reagents, unless otherwise specified, were purchased from Sigma-Aldrich (SigmaAldrich, St. Louis, MO, USA), and used without any further purification.

\section{Experimental procedures}

General procedure for the synthesis of 2-azido

\section{ketones 2d, 2e, 2f, 2k, 2I and $\mathbf{2 m}$}

$\alpha$-Haloketone $1(1.5 \mathrm{mmol})$ and $\mathrm{NaN}_{3}(107 \mathrm{mg}, 1.65 \mathrm{mmol})$ were sequentially added to the $\mathrm{ChCl} / \mathrm{Gly}(1: 2 \mathrm{~mol} / \mathrm{mol}, 2.0 \mathrm{~g})$ eutectic mixture. The reaction mixture was stirred at $25{ }^{\circ} \mathrm{C}$ under air for 3-12 h until complete consumption of the starting material (monitored by thin-layer chromatography). Then, water was added, and the mixture was extracted with EtOAc $(3 \times 10 \mathrm{~mL})$. The collected organic layers were dried using anhydrous $\mathrm{Na}_{2} \mathrm{SO}_{4}$, filtered, and the volatile evaporated under reduced pressure to afford the crude product, which was puri- fied by column chromatography on silica gel (hexane/EtOAc $5: 1-4: 1)$ to afford the desired $\alpha$-azido ketone 2 . Characterization data of the isolated 2-azido ketones are provided in Supporting Information File 1.

Synthesis of 2-benzoyl-4-phenyl-1H-imidazole (3a) and 2-benzoyl-5-phenyl-1H-imidazole (3a'). Typical procedure

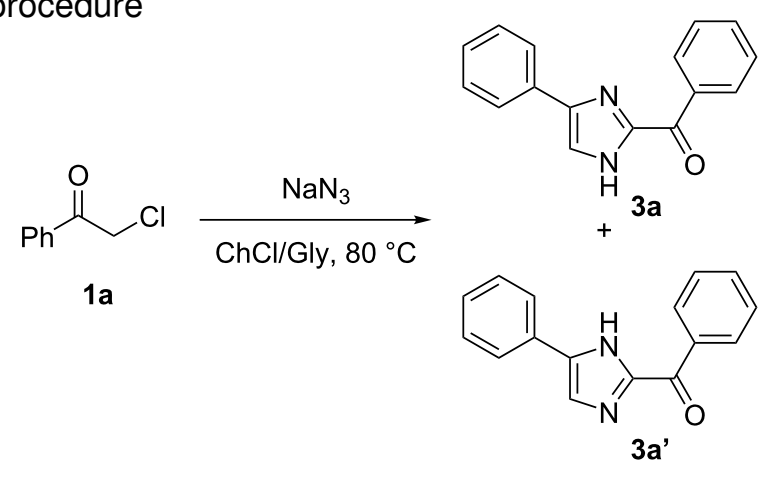

Sodium azide $(0.75 \mathrm{mmol})$ was added to a solution of 2-chloroacetophenone (1a, $0.5 \mathbf{m m o l})$ in $\mathrm{ChCl} / \mathrm{Gly}$ $(1: 2 \mathrm{~mol} / \mathrm{mol}, 1.0 \mathrm{~g})$ under air and with vigorous stirring. The mixture was then warmed to $80{ }^{\circ} \mathrm{C}$. After $12 \mathrm{~h}, 10 \mathrm{~mL}$ of water were added and the solid 3a was recovered by decantation (or filtration) from the reaction mixture and washed with a few drops of EtOAc or $\mathrm{Et}_{2} \mathrm{O}$. The solution was extracted with EtOAc $(3 \times 10 \mathrm{~mL})$. The combined organic phases were dried over anhydrous $\mathrm{Na}_{2} \mathrm{SO}_{4}$ and the solvent was concentrated in vacuo. The addition of $\mathrm{Et}_{2} \mathrm{O}$ to the crude mixture allowed the further precipitation of $\mathbf{3 a}$, which was finally recovered in $88 \%$ yield. Characterization data of the isolated imidazoles are provided in Supporting Information File 1.

\section{Synthesis of 2,4-dibenzoyl-6-phenylpyrimidine (7a).} Typical procedure

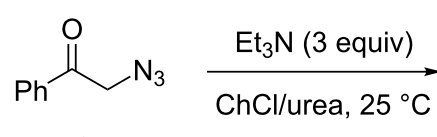

$2 a$<smiles>O=C(c1ccccc1)c1cc(-c2ccccc2)nc(-c2ccccc2)n1</smiles>

$\mathrm{Et}_{3} \mathrm{~N}(0.930 \mathrm{mmol}, 0.130 \mathrm{~mL})$ was added to a solution of 2-azidoacetophenone (2a, $0.31 \mathrm{mmol}, 0.05 \mathrm{~g}$ ) in $\mathrm{ChCl} /$ urea $(1: 2 \mathrm{~mol} / \mathrm{mol}, 0.5 \mathrm{~g})$ eutectic mixture at $25{ }^{\circ} \mathrm{C}$, under air and with vigorous stirring. The reaction was monitored by TLC (hexane/EtOAc 7:3). After $4 \mathrm{~h}, 5 \mathrm{~mL}$ of water were added and the reaction mixture was extracted with EtOAc $(3 \times 5 \mathrm{~mL})$. The combined organic phases were dried over anhydrous $\mathrm{Na}_{2} \mathrm{SO}_{4}$ and the solvent was concentrated under reduced pressure. Purification by column chromatography on silica gel (hexane/ EtOAc 9:1) provided pyrimidine $\mathbf{7 a}$ in $57 \%$ yield. A mixture of 
imidazoles 3a/3a' (43\% yield) was also isolated. Characterization data of the isolated pyrimidines are provided in Supporting Information File 1.

\section{Supporting Information}

\section{Supporting Information File 1}

Compound characterization data and NMR spectra.

[https://www.beilstein-journals.org/bjoc/content/

supplementary/1860-5397-16-158-S1.pdf]

\section{Acknowledgements}

The authors are also indebted to Dr. Francesco Lavolpe, Dr. Walter Barella, Dr. Giuseppe Dilauro, and Dr. Francesco Messa for their contribution to the experimental work.

\section{Funding}

This work was carried out under the framework of the national PRIN project "Unlocking Sustainable Technologies Through Nature-inspired Solvents (NATUREChem) (grant number: 2017A5HXFC_002) financially supported by the University of Bari "A. Moro" (codes: SFARMA.RicercaLocale.Vitale Fondi Ateneo 17-18, PernaF.18 FondiAteneo15-16, VitaleP.18 FondiAteneo15-16), the University of Salento, the Interuniversity Consortium C.I.N.M.P.I.S., and the Ministero dell’Università e della Ricerca (MIUR-PRIN).

\section{ORCID ${ }^{\circledR}$ iDs}

Paola Vitale - https://orcid.org/0000-0001-8132-2893 Luciana Cicco - https://orcid.org/0000-0003-4126-3993 Filippo M. Perna - https://orcid.org/0000-0002-8735-8165 Antonio Salomone - https://orcid.org/0000-0002-3161-385X Vito Capriati - https://orcid.org/0000-0003-4883-7128

\section{References}

1. Alonso, D. A.; Baeza, A.; Chinchilla, R.; Guillena, G.; Pastor, I. M.; Ramón, D. J. Eur. J. Org. Chem. 2016, 612-632. doi:10.1002/ejoc.201501197

2. Ramón, D. J.; Guillena, G., Eds. Deep Eutectic Solvents: Synthesis, Properties, and Applications; Wiley-VCH: Weinheim, Germany, 2019. doi:10.1002/9783527818488

3. Perna, F. M.; Vitale, P.; Capriati, V. Curr. Opin. Green Sustainable Chem. 2020, 21, 27-33. doi:10.1016/j.cogsc.2019.09.004

4. Cicco, L.; Sblendorio, S.; Mansueto, R.; Perna, F. M.; Salomone, A.; Florio, S.; Capriati, V. Chem. Sci. 2016, 7, 1192-1199. doi:10.1039/c5sc03436a

5. Capua, M.; Perrone, S.; Perna, F. M.; Vitale, P.; Troisi, L.; Salomone, A.; Capriati, V. Molecules 2016, 21, 924. doi:10.3390/molecules21070924
6. Mancuso, R.; Maner, A.; Cicco, L.; Perna, F. M.; Capriati, V.; Gabriele, B. Tetrahedron 2016, 72, 4239-4244. doi:10.1016/j.tet.2016.05.062

7. Perrone, S.; Capua, M.; Messa, F.; Salomone, A.; Troisi, L. Tetrahedron 2017, 73, 6193-6198. doi:10.1016/j.tet.2017.09.013

8. Behalo, M. S.; Bloise, E.; Mele, G.; Salomone, A.; Messa, F.; Carbone, L.; Mazzetto, S. E.; Lomonaco, D. J. Heterocycl. Chem. 2020, 57, 768-773. doi:10.1002/jhet.3818

9. Dilauro, G.; Cicco, L.; Perna, F. M.; Vitale, P.; Capriati, V. C. R. Chim. 2017, 20, 617-623. doi:10.1016/j.crci.2017.01.008

10. Ghinato, S.; Dilauro, G.; Perna, F. M.; Capriati, V.; Blangetti, M.; Prandi, C. Chem. Commun. 2019, 55, 7741-7744. doi:10.1039/c9cc03927a

11. Messa, F.; Perrone, S.; Capua, M.; Tolomeo, F.; Troisi, L.; Capriati, V.; Salomone, A. Chem. Commun. 2018, 54, 8100-8103. doi:10.1039/c8cc03858a

12. Dilauro, G.; García, S. M.; Tagarelli, D.; Vitale, P.; Perna, F. M.; Capriati, V. ChemSusChem 2018, 11, 3495-3501. doi:10.1002/cssc.201801382

13. Messa, F.; Dilauro, G.; Perna, F. M.; Vitale, P.; Capriati, V.; Salomone, A. ChemCatChem 2020, 12, 1979-1984. doi:10.1002/cctc.201902380

14. Quivelli, A. F.; Vitale, P.; Perna, F. M.; Capriati, V. Front. Chem. (Lausanne, Switz.) 2019, 7, 723. doi:10.3389/fchem.2019.00723

15. Vitale, P.; Lavolpe, F.; Valerio, F.; Di Biase, M.; Perna, F. M.; Messina, E.; Agrimi, G.; Pisano, I.; Capriati, V. React. Chem. Eng. 2020, 5, 859-864. doi:10.1039/d0re00067a

16. Vitale, P.; Cicco, L.; Messa, F.; Perna, F. M.; Salomone, A.; Capriati, V. Eur. J. Org. Chem. 2019, 5557-5562. doi:10.1002/ejoc.201900722

17. De Luca, L. Curr. Med. Chem. 2006, 13, 1-23.

18. Lagoja, I. M. Chem. Biodiversity 2005, 2, 1-50. doi:10.1002/cbdv.200490173

19. Han, H.-B.; Tu, Z.-L.; Wu, Z.-G.; Zheng, Y.-X. Dyes Pigm. 2019, 160, 863-871. doi:10.1016/j.dyepig.2018.09.017

20. Chen, W.-C.; Zhu, Z.-L.; Lee, C.-S. Adv. Opt. Mater. 2018, 6, 1800258. doi:10.1002/adom.201800258

21. Zhang, L.; Peng, X.-M.; Damu, G. L. V.; Geng, R.-X.; Zhou, C.-H. Med. Res. Rev. 2014, 34, 340-437. doi:10.1002/med.21290

22. Sharma, A.; Kumar, V.; Kharb, R.; Kumar, S.; Chander Sharma, P.; Pal Pathak, D. Curr. Pharm. Des. 2016, 22, 3265-3301. doi:10.2174/1381612822666160226144333

23. Kuzu, B.; Tan, M.; Taslimi, P.; Gülçin, I.; Taşpınar, M.; Menges, N. Bioorg. Chem. 2019, 86, 187-196. doi:10.1016/j.bioorg.2019.01.044

24. Agarwal, A.; Srivastava, K.; Puri, S. K.; Chauhan, P. M. S. Bioorg. Med. Chem. 2005, 13, 4645-4650. doi:10.1016/j.bmc.2005.04.061

25. Shipe, W. D.; Sharik, S. S.; Barrow, J. C.; McGaughey, G. B.; Theberge, C. R.; Uslaner, J. M.; Yan, Y.; Renger, J. J.; Smith, S. M.; Coleman, P. J.; Cox, C. D. J. Med. Chem. 2015, 58, 7888-7894. doi:10.1021/acs.jmedchem.5b00983

26. Kaur, R.; Kaur, P.; Sharma, S.; Singh, G.; Mehndiratta, S.; Bedi, P. M. S.; Nepali, K. Recent Pat. Anti-Cancer Drug Discovery 2015, 10, 23-71. doi:10.2174/1574892809666140917104502

27. Farag, A. K.; Elkamhawy, A.; Londhe, A. M.; Lee, K.-T.; Pae, A. N.; Roh, E. J. Eur. J. Med. Chem. 2017, 141, 657-675. doi:10.1016/j.ejmech.2017.10.003

28. Chen, J.; Chen, W.; Yu, Y.; Zhang, G. Tetrahedron Lett. 2013, 54 , 1572-1575. doi:10.1016/j.tetlet.2013.01.042 
29. Khalili, B.; Tondro, T.; Hashemi, M. M. Tetrahedron 2009, 65, 6882-6887. doi:10.1016/j.tet.2009.06.082

30. Batanero, B.; Escudero, J.; Barba, F. Org. Lett. 1999, 1, 1521-1522. doi:10.1021/ol990200j

31. Benati, L.; Leardini, R.; Minozzi, M.; Nanni, D.; Spagnolo, P.; Strazzari, S.; Zanardi, G.; Calestani, G. Tetrahedron 2002, 58 , 3485-3492. doi:10.1016/s0040-4020(02)00302-2

32. Zuliani, V.; Cocconcelli, G.; Fantini, M.; Ghiron, C.; Rivara, M. J. Org. Chem. 2007, 72, 4551-4553. doi:10.1021/jo070187d

33. Yamamoto, Y.; Ouchi, H.; Tanaka, T.; Morita, Y. Heterocycles 1995, 41, 1275-1290. doi:10.3987/com-95-7055

34. Skulcova, A.; Russ, A.; Jablonsky, M.; Sima, J. BioResources 2018, 13, 5042-5051.

35. Boyer, J. H.; Straw, D. J. Am. Chem. Soc. 1952, 74, 4506-4508. doi:10.1021/ja01138a011

36. Patonay, T.; Juhász-Tóth, É.; Bényei, A. Eur. J. Org. Chem. 2002, 285-295. doi:10.1002/1099-0690(20021)2002:2<285::aid-ejoc285>3.0.co;2-j

37. Mjalli, F. S.; Ahmed, O. U. Korean J. Chem. Eng. 2016, 33, 337-343. doi:10.1007/s11814-015-0134-7

38. Reddy, C. N.; Sathish, M.; Adhikary, S.; Nanubolu, J. B.; Alarifi, A.; Maurya, R. A.; Kamal, A. Org. Biomol. Chem. 2017, 15, 2730-2733. doi:10.1039/c7ob00299h

39. Hu, M.; Wu, J.; Zhang, Y.; Qiu, F.; Yu, Y. Tetrahedron 2011, 67, 2676-2680. doi:10.1016/j.tet.2011.01.062

\section{License and Terms}

This is an Open Access article under the terms of the Creative Commons Attribution License (http://creativecommons.org/licenses/by/4.0). Please note that the reuse, redistribution and reproduction in particular requires that the authors and source are credited.

The license is subject to the Beilstein Journal of Organic Chemistry terms and conditions:

(https://www.beilstein-journals.org/bjoc)

The definitive version of this article is the electronic one which can be found at: $\underline{\text { doi: } 10.3762 / \text { bjoc. } 16.158}$ 